\title{
Prevalence and correlates for school truancy among pupils in grades 7-10: results from the 2004 Zambia Global School-based Health Survey
}

\author{
Adamson S Muula', Emmanuel Rudatsikira², Olusegun Babaniyi ${ }^{3}$, Peter Songolo ${ }^{3}$ and Seter Siziya ${ }^{4 *}$
}

\begin{abstract}
Background: There are limited data on the prevalence and associated factors of truancy in southern Africa. Yet truancy should attract the attention of public health professionals, educators and policy makers as it may be associated with adolescent problem behaviours. The objectives of the study were to estimate the prevalence and determine correlates of school truancy among pupils in Zambia.

Findings: We used data collected in 2004 in the Zambia Global School-based Health Survey. Logistic regression analysis was conducted to identify factors associated with truancy. A total of 2257 pupils participated in the survey of whom $53.9 \%$ were male. Overall $58.8 \%$ of the participants (58.1\% of males and $58.4 \%$ of females) reported being truant in the past 30 days. Factors associated with truancy were having been bullied (AOR $=1.34,95 \% \mathrm{Cl}[1.32$, 1.36]), current alcohol use (AOR $=2.19,95 \% \mathrm{Cl}[2.16,2.23])$, perception that other students were kind and helpful $(\mathrm{AOR}=1.12,95 \% \mathrm{Cl}[1.10,1.14])$, being male and being from the lowest school grade. Pupils whose parents or guardians checked their homework (AOR $=0.9195 \% \mathrm{Cl}$, [0.89, 0.92]) and those who reported parental supervision $(\mathrm{AOR}=0.94,95 \% \mathrm{Cl}[0.92-0.95])$ were less likely to report being truant.

Conclusions: We found a high prevalence of truancy among pupils in grades 7-10 in Zambia. Interventions aimed to reduce truancy should be designed and implemented with due consideration of the associated factors.
\end{abstract}

\section{Background}

There is growing health-related literature of truancy and its predictors from the developed world, but not much has been reported from the developing world. The potential consequences of truancy as a social problem spans across reproductive and sexual health, mental health, pulmonary health, injury experience, adult underachievement and poverty [1-4].

To explain why truancy may be associated with harmful behaviours, Henry and Huizinga [5] argued that the unsupervised and unmonitored time with peers may facilitate exposure to potentially harmful lifestyles such as illicit drug use. Olley [6] found that $46 \%$ of street youth (who lacked parental supervision) in Ibadan, Nigeria reported history of truancy.

\footnotetext{
* Correspondence: ssiziya@gmail.com

${ }^{4}$ Department of Community Medicine, School of Medicine, University of Zambia, Lusaka, Zambia

Full list of author information is available at the end of the article
}

The role of formal education in promoting health and social well-being cannot be over-emphasized. And yet the attainment of education by pupils can be disturbed by truant behaviours. We therefore carried out this study to estimate the prevalence and associated factors of school truancy among pupils in grades 7-10 in Zambia. This information is potentially useful in designing programs that may reduce the problem of truancy in the country.

\section{Methods}

This study involved analysis of data from the Zambia Global School-based Health Survey (GSHS) that was conducted in 2004. Developed by the World Health Organization (WHO) in collaboration with UNICEF, UNESCO, and UNAIDS with technical assistance from the Centres for Diseases Control and Prevention (CDC), Atlanta, Georgia, United States, the GSHS aims to provide data on health and social behaviours among in-

\section{Ciomed Central}


school adolescents. Further details of the GSHS have been reported elsewhere [7-10].

In Zambia, pupils from grades 7-10 were recruited. Although 3021 pupils were eligible to participate in the survey, only 2257 eventually participated, giving a response rate of $75 \%$. The survey used a two-stage probability sampling technique. In the first stage of sampling, the primary sampling units were schools. These were selected with a probability proportional to their enrolment size. In the second step, a systematic sample of classes in the selected school was obtained. All pupils in the selected classes were eligible to participate.

The data are de-identified and are in public domain with global authorization for re-use. Prior to commencement of the survey, permission to carry out the study was obtained from the Ministries of Health and Education. Informed consent to participate in the study was obtained from school managers and students. Students anonymously and voluntarily completed the questionnaire.

The completion of the questionnaire occurred within one class period. Pupils were encouraged to answer all questions but also told that they were free not to answer any question they felt uncomfortable with. A total of 12 trained research assistants supervised the process. Pupils were asked: During the past 30 days, on how many days did you miss classes or school without permission? The responses were 0 days, 1 or 2 days, 3-5 days, 6-9 days and 10 or more days. A binary variable was created where a response of 0 was recoded as having never missed school or class (0) while any number of days $>0$ was recoded as 1 . Regarding the predictor variables, pupils were asked the following questions: During the past 30 days, how often did you go hungry because there was not enough food in your home? During the past 30 days, how often were most of the students in your school kind and helpful? During the past 30 days, how often did you parents or guardians check to see if your homework was done? During the past 30 days, how often did your parents or guardians really know what you were doing with your free time? The responses to the above predictor variables were never, rarely, sometimes, most of the time, and always. These responses were categorized into a yes (combined rarely, sometimes, most of the time and always) or a no. The responses for the other two predictor variables: "During the past 30 days, on how many days did you have at least one drink containing alcohol?" and "During the past 30 days, on how many days were you bullied?" were 0 days, 1 or 2 days, 3-5 days, 6-9 days, 10-19 days, 20-29 days and all 30 days. The responses were categorized into a yes (having been bullied for at least 1 day in the past 30 days) or a no.

\section{Data analysis}

Data analysis was performed using SPSS version 14.0 software. The outcome variable was history of truancy. Due to the nature of the study design a weighting factor was used in the analysis to reflect the likelihood of sampling each pupil and to reduce bias by compensating for differing patterns of non response.

We obtained frequencies to describe the sample and estimate the prevalence of truancy. We conducted logistic regression in bivariate analyses and multivariate logistic regression analysis using the backward variable selection method to estimate associations between relevant predictor variables and truancy within the last 30 days. We report unadjusted odds ratios (OR) together with their 95\% confidence intervals (CI) for selected predictor variables while considering having been truant in the last 30 days as a dependent variable. We also report adjusted odds ratios (AOR) and their CI from a multivariate analysis considering factors that were significantly associated with the outcome in bivariate analyses.

\section{Results}

A total of 2257 pupils participated in the Zambian Global School-based Health Survey that was conducted in 2004. Of those whose data were available, $53.9 \%$ were male. Overall $58.8 \%$ of the participants $(58.1 \%$ of males and $58.4 \%$ of females) reported being truant in the past 30 days, while $42.2 \%$ were current drinkers, and $62.8 \%$ reported having been bullied in the past 30 days. Further description of the study sample is shown in Table 1.

In bivariate logistic regression analyses (Table 2), we found that pupils in the youngest age group $<14$ years were less likely to be truant compared to pupils who were aged 16 years or older. However, pupils who were in the middle age categories were more likely to be truant. In other results of bivariate analyses we found that current alcohol use, having been bullied, perception that peers were helpful and kind and having gone hungry because of lack of food at home were associated with truancy. Gender and parental supervision were not associated with truancy, while parental support with homework was negatively associated with the outcome.

In a multivariate analysis (Table 2), age, sex, school grade, perception that other students were kind and helpful, history of being bullied, alcohol use, perception that peers were helpful, parents or guardians checked their homework, parental supervision, and having been bullied were significantly associated with truancy.

Participants who were bullied $(\mathrm{AOR}=1.34,95 \% \mathrm{CI}$ $[1.32,1.36])$, consumed alcohol $(\mathrm{AOR}=2.19,95 \% \mathrm{CI}$ $[2.16,2.23])$, perceived that other students were kind and helpful $(\mathrm{AOR}=1.12,95 \% \mathrm{CI}[1.10,1.14])$, male and from the lowest school grade were more likely to report 
Table 1 Socio-demographic and truancy characteristics of pupils in grades 7-10 in Zambia, 2004

\begin{tabular}{|c|c|c|c|}
\hline Factor & $\begin{array}{l}\text { Total } \\
\mathrm{n}^{*}(\%)^{* *}\end{array}$ & $\begin{array}{l}\text { Male } \\
\mathrm{n}^{*}(\%)^{* *}\end{array}$ & $\begin{array}{l}\text { Female } \\
n^{*}(\%)^{* *}\end{array}$ \\
\hline \multicolumn{4}{|l|}{ Age } \\
\hline$<14$ & $463(27.5)$ & $156(21.5)$ & $263(30.9)$ \\
\hline 14 & $386(19.1)$ & $156(17.4)$ & 219 (21.6) \\
\hline 15 & $513(22.8)$ & $260(24.5)$ & $238(21.6)$ \\
\hline $16+$ & $708(30.6)$ & $394(36.5)$ & $306(25.9)$ \\
\hline \multicolumn{4}{|l|}{ Sex } \\
\hline Male & 994 (53.9) & - & - \\
\hline Female & $1039(46.1)$ & & \\
\hline \multicolumn{4}{|l|}{ Grade } \\
\hline 7 & $840(56.5)$ & $344(55.1)$ & $463(57.3)$ \\
\hline 8 & $552(20.7)$ & $291(21.0)$ & $241(20.4)$ \\
\hline 9 or 10 & $670(22.8)$ & $343(23.9)$ & $317(22.3)$ \\
\hline \multicolumn{4}{|l|}{ Hungry } \\
\hline Yes & $1691(82.5)$ & $787(82.3)$ & $834(83.4)$ \\
\hline No & $366(17.5)$ & $173(17.7)$ & $170(16.6)$ \\
\hline \multicolumn{4}{|c|}{ Peers kind and helpful } \\
\hline Yes & $1292(74.4)$ & $592(73.2)$ & $636(75.9)$ \\
\hline No & $452(25.6)$ & $222(26.8)$ & $210(24.1)$ \\
\hline \multicolumn{4}{|c|}{ Parents checked homework } \\
\hline Yes & $1339(74.5)$ & $602(73.1)$ & $679(77.0)$ \\
\hline No & $448(25.5)$ & $224(26.9)$ & $197(23.0)$ \\
\hline \multicolumn{4}{|c|}{ Parental supervision } \\
\hline Yes & $1369(77.4)$ & $634(78.1)$ & $673(77.2)$ \\
\hline No & $377(22.6)$ & $169(21.9)$ & $189(22.9)$ \\
\hline \multicolumn{4}{|l|}{ Bullied } \\
\hline Yes & $949(62.8)$ & $431(60.0)$ & $466(65.0)$ \\
\hline No & $610(37.2)$ & $314(40.0)$ & $274(35.0)$ \\
\hline \multicolumn{4}{|c|}{ Current alcohol drinking } \\
\hline Yes & $528(42.2)$ & $217(38.5)$ & $283(45.1)$ \\
\hline No & $805(57.8)$ & $388(61.5)$ & $388(54.9)$ \\
\hline \multicolumn{4}{|c|}{ Missed classes or school } \\
\hline Yes & $1010(58.8)$ & $365(58.1)$ & $381(58.4)$ \\
\hline No & $772(41.2)$ & $463(41.9)$ & $493(41.6)$ \\
\hline
\end{tabular}

Frequencies not adding up because of missing information

* unweighted frequencies

** weighted percents

being truant. Pupils whose parents or guardians checked their homework $(\mathrm{AOR}=0.9195 \% \mathrm{CI},[0.89,0.92])$ and those who reported parental supervision $(\mathrm{AOR}=0.94$, 95\% CI [0.92-0.95]) were less likely to report being truant.

\section{Discussion}

We found the prevalence of truancy within the last 30 days to be $58.8 \%$ among pupils in grades 7-10 in Zambia. This rate was much higher than what we found in Swaziland of $21.6 \%$ [11]. In a study of 8 th and 10 th graders in the United States, Henry reported that $11 \%$ of the former and $16 \%$ of 10 th graders reported recent
Table 2 Factors associated with truancy among pupils in grades 7-10 in Zambia, 2004

\begin{tabular}{|c|c|c|}
\hline Factor & $\mathrm{OR}^{*}\left(95 \% \mathrm{Cl}^{* *}\right)$ & $\mathrm{AOR}^{* * *}(95 \% \mathrm{Cl})$ \\
\hline \multicolumn{3}{|l|}{ Age } \\
\hline$<14$ & $0.90(0.88,0.91)$ & $0.67(0.65,0.68)$ \\
\hline 14 & $1.15(1.13,1.16)$ & $1.08(1.05,1.11)$ \\
\hline 15 & $1.04(1.03,1.06)$ & $1.12(1.09,1.15)$ \\
\hline $16+$ & 1 & 1 \\
\hline \multicolumn{3}{|l|}{ Sex } \\
\hline Male & $1.00(0.99,1.00)$ & $1.16(1.14,1.18)$ \\
\hline Female & 1 & 1 \\
\hline \multicolumn{3}{|l|}{ Grade } \\
\hline 7 & $1.21(1.19,1.22)$ & $1.41(1.38,1.44)$ \\
\hline 8 & $1.03(1.02,1.04)$ & $0.92(0.90,0.94)$ \\
\hline 9 or 10 & 1 & 1 \\
\hline \multicolumn{3}{|l|}{ Hungry } \\
\hline Yes & $1.17(1.16,1.18)$ & - \\
\hline No & 1 & \\
\hline \multicolumn{3}{|c|}{ Peers kind and helpful } \\
\hline Yes & $1.02(1.01,1.03)$ & $1.12(1.10,1.14)$ \\
\hline No & 1 & 1 \\
\hline \multicolumn{3}{|c|}{ Parents checked homework } \\
\hline Yes & $1.00(0.99,1.01)$ & $0.91(0.89,0.92)$ \\
\hline No & 1 & 1 \\
\hline \multicolumn{3}{|c|}{ Parental supervision } \\
\hline Yes & $0.95(0.94,0.96)$ & $0.94(0.92,0.95)$ \\
\hline No & 1 & 1 \\
\hline \multicolumn{3}{|l|}{ Bullied } \\
\hline Yes & $1.82(1.80,1.84)$ & $1.34(1.32,1.36)$ \\
\hline No & 1 & 1 \\
\hline \multicolumn{3}{|c|}{ Current alcohol drinking } \\
\hline Yes & $2.52(2.49,2.54)$ & $2.19(2.16,2.23)$ \\
\hline No & 1 & 1 \\
\hline
\end{tabular}

$O R^{*}$ Unadjusted odds ratio; $C l^{* *}$ Confidence Interval; $A O R^{* * *}$ Adjusted odds ratio for all the significant factors in a multivariate analysis

truancy in past 4 weeks [12]. The high rate of truancy in this study may be due to the high rate of alcohol use (42.2\%) compared to $16.6 \%$ in Swaziland [11]. It is also possible that adolescents from poor households may miss school to work at home or elsewhere.

Like in other studies, we found that males were at increased likelihood of being truant than females. Siziya et al. [11] reported that, in Swaziland, male adolescents were more likely to be truant than females. Likewise in United States, Weden and Zabin [13] reported that males were more likely to engage in problem behaviours, including being truant among adolescents in the National Longitudinal Survey of Youth (1997-2000). We also found that pupils who were of ages less than 14 years were less likely to be truant than older pupils. Younger pupils are more likely to be under parental supervision than older pupils and may thus be less likely to be truant than older pupils. The finding on the 
association of grade with truancy was inconsistent. While pupils in grade 7 were more likely to be truant than those in grades 9 or 10, those in grade 8 were less likely to be truant. It is inconceivable that pupils in examination grades (grades 7 and 9) could be more likely to be truant than those in a non examination grade 8 when they should not be missing classes to prepare for their examinations. We offer no explanation for this observation.

In our study, pupils who felt that their peers were kind and helpful were more likely to be truant. In a study of school-related risk and protective factors associate with truancy among urban youth placed at risk, Henry and Huizinga (2007) found that having delinquent peers was a strong predictor of truancy [14]. It is possible that truant students, who constitute the majority of the respondents in this study, may be kind and supportive to those who are involved in the same behaviour.

We found that pupils who reported that their parents or guardians checked their homework or reported that they received parental supervision were less likely to be truant. In a randomized controlled trial, Stanton et al. [15] found that parental involvement with and support of the adolescent was associated with less truancy and other problem behaviours. Henry [12] also found that a large amount of unsupervised time was associated with truancy. Parental supervision is an important determinant of truancy in many settings $[11,15]$. In another study by Miller and Plant [16], however, parental caring and control were not significantly associated with truancy.

We also found that study participants who reported being victims of bullying were more likely to have been truant. It is possible that adolescents who are bullied may miss school in order to escape further victimization. While truancy is a problem behaviour on its own, it is important that parents and school authorities explore the reasons why a pupil may be missing school without permission. A bully-free school may reduce the prevalence of truancy $[17,18]$.

Alcohol consumption was significantly associated with truancy in the current study. This finding was similar to that previously reported from Swaziland [11]. Best et al. [3] have also reported among 14-16 year olds in the United Kingdom that excessive alcohol drinking was associated with frequent truancy. In that study excessive drinking was defined as drinking 10 or more units of alcohol on one occasion.

Our study had a few limitations. Firstly the study was based on data based on self reports. Pupils may have misreported either due to failure to recall or misreported intentionally. Completion of the study questionnaire was done anonymously so as to maintain confidentiality and reduce possibility of intentional misreporting. Also data were collected from pupils who were available in school on the day of the survey. Pupils who were absent being both truant and otherwise were not included, and thus we may have underestimated the prevalence of truancy. Although the responses to the predictor variables were obtained as categories, we further dichotomized them, and this may have reduced the statistical power in the analysis.

\section{Conclusions}

Our study found the prevalence of school truancy within the past 30 days among pupils in grades $7-10$ in Zambia to be $58.8 \%$. Factors such as current alcohol drinking and being bullied, which have been reported elsewhere as predictors of truancy, were also identified in our study. Designing of intervention programs aimed to reduce truancy in Zambia should consider these factors.

\section{Acknowledgements}

We are thankful to the Centers for Disease Control and Prevention (CDC), Atlanta, Georgia, United States for making the data set available, and the World Health Organization through its Zambia country office for funding the survey. We are grateful to the pupils who participated in the survey.

\section{Author details}

'Department of Community Health, College of Medicine, University of Malawi, Blantyre, Malawi. ${ }^{2}$ School of Community and Environmental Health, Old Dominion University, Norfolk, VA, USA. ${ }^{3}$ World Health Organization Country Office, Lusaka, Zambia. ${ }^{4}$ Department of Community Medicine, School of Medicine, University of Zambia, Lusaka, Zambia.

\section{Authors' contributions}

ASM participated in the interpretation of the data and led the drafting of the manuscript. ER helped in data analysis and interpretation and revision of the manuscript. OB and PS were involved in drafting the manuscript or revising it critically for important intellectual content. SS carried out data analysis and participated in the drafting of the manuscript. All authors read and approval the final manuscript.

\section{Competing interests}

The authors declare that they have no competing interests.

Received: 22 September 2011 Accepted: 20 January 2012 Published: 20 January 2012

\section{References}

1. Petrides KV, Chamorro-Premuzic T, Frederickson N, Furnham A: Explaining individual differences in scholastic behaviour and achievement. $\mathrm{Br} J$ EduC Psychol 2005, 75:239-255.

2. Kokkevi AE, Arapaki AA, Richardson C, Florescu S, Kuzman M, Stergar E: Further investigation of psychological and environmental correlates of substance use in adolescence in six European countries. Drug Alcohol Depend 2007, 88:308-312.

3. Best D, Manning V, Gossop M, Gross S, Strang J: Excessive drinking and other problem behaviours among 14-16 year old schoolchildren. Addict Behav 2006, 31:1424-1435.

4. Peltzer K: Injury and social determinants among in-school adolescents in six African countries. Inj Prev 2008, 14:381-388.

5. Henry KL, Huizinga DH: Truancy's effect on the onset of drug use among urban adolescents placed at risk. J Adolesc Health 2007, 40:358, e9-e17.

6. Olley BO: Social and health behaviors in youth of the streets of Ibadan, Nigeria. Child Abuse Negl 2006, 30:271-282. 
7. Siziya S, Rudatsikira E, Muula AS: Alcohol use among school-going adolescents in Harare, Zimbabwe: results from the 2003 Global SchoolBased Health Survey. Tanzan J Health Res 2009, 11:11-16.

8. Swahn MH, Ali B, Palmier JB, Sikazwe G, Mayeya J: Alcohol Marketing, Drunkenness, and Problem Drinking among Zambian Youth: Finding from the 2004 Global School-Based Student Health Survey. J Environ Public Health 2011, 497827, 2011 (ePub).

9. Hazemba A, Siziya S, Muula AS, Rudatsikira E: Prevalence and correlates of being bullied among in-school adolescents in Beijing: results from the 2003 Beijing Global school-based Health Survey. Ann Gen Psychiatry 2008, 7:6-10.

10. Chinsembu KC, Siziya S, Rudatsikira E, Muula AS: Prevalence and social correlates of sexual intercourse among in-school adolescents in Namibia. Sahara J 2008, 5:129-135.

11. Siziya S, Muula AS, Rudatsikira E: Prevalence and correlates of truancy among adolescents in Swaziland: findings from the Global School-based Health Survey. Child Adolesc Psychiatry Ment Health 2007, 1:15.

12. Henry KL: Who's skipping school: characteristics of truants in 8th and 10th grade. I Sch Health 2007, 77:29-35.

13. Weden MM, Zabin LS: Gender and ethnic differences in the cooccurrence of adolescent risk behaviors. Ethn Health 2005, 10:213-234.

14. Henry KL, Huizinga DH: School-related risk and protective factors associated with truancy among urban youth placed at risk. J Prim Prev 2007, 28:505-519.

15. Stanton B, Cole M, Galbraith J, Li X, Pendleton S, Cottrel L, Marshall S, Wu Y, Kaljee $L$ : Randomized trial of a parent intervention: parents can make a difference in long-term adolescent risk behaviors, perceptions, and knowledge. Arch Pediatr Adolesc Med 2004, 158:947-955.

16. Miller P, Plant M: Truancy and perceived school performance: an alcohol and drug study of UK teenagers. Alcohol Alcohol 1999, 34:886-893.

17. Vreeman RC, Carroll AE: A systematic review of school-based interventions to prevent bullying. Arch Pediatr Adolesc Med 2007, 161:78-88.

18. Kim YS, Leventhal BL, Koh YJ, Hubbard A, Boyce WT: School bullying and youth violence: causes or consequences of psychopathologic behavior? Arch Gen Psychiatry 2006, 63:1035-1041.

doi:10.1186/1756-0500-5-48

Cite this article as: Muula et al:: Prevalence and correlates for schoo truancy among pupils in grades 7-10: results from the 2004 Zambia Global School-based Health Survey. BMC Research Notes 2012 5:48.

\section{Submit your next manuscript to BioMed Central and take full advantage of:}

- Convenient online submission

- Thorough peer review

- No space constraints or color figure charges

- Immediate publication on acceptance

- Inclusion in PubMed, CAS, Scopus and Google Scholar

- Research which is freely available for redistribution

Submit your manuscript at www.biomedcentral.com/submit 